\title{
Comparative Cross-sectional Quantitative Study of Health Status among Consumers of Bitter Kola in Igbuzor Community Living in Oshilmili North Local Government Area of Delta State
}

\author{
Vincent Icheku ${ }^{1, *}$, Ifeanyichukwu Fidelis Onianwah ${ }^{2}$, Augustine Nwulia ${ }^{3}$ \\ ${ }^{1}$ Senior Lecturer, School of Health and Social Care, London South Bank University, England \\ ${ }^{2}$ Senior Research Fellow, Rexall Laboratory Research Services, Port Harcourt, Nigeria \\ ${ }^{3}$ Research Fellow, Faculty of Humanities, University of Port Harcourt, Nigeria
}

Copyright $\bigcirc 2018$ by authors, all rights reserved. Authors agree that this article remains permanently open access under the terms of the Creative Commons Attribution License 4.0 International License

\begin{abstract}
Background: The use of bitter kola as plant medicine is common among Africans for centuries, yet there is little or no scientific evidence to demonstrate that its use provides health benefits. The purpose of this study, therefore, is to ascertain whether or not bitter kola provides any health benefits to its regular users. Methods: A study sample of $n=274$ adults living in Igbuzor town in Oshimili North Local Government Area of Delta State of Nigeria was selected using simple random sampling technique. Likert Scale was used as data collection tool. The data analysis was carried out using SPSS computer software. Results: The results show that irrespective of gender $\mathrm{n}=139$ regular users agreed to excellent and good health while ingesting bitter kola in comparison to $n=37$ non-regular users who agreed to the same statements (see table $3 \& 4)$. The results further show that both genders $\mathrm{n}=142 \quad(94.66 \%)$ male and $\mathrm{n}=110 \quad(95.65 \%)$ female respondents agree that they ingest better kola for its health benefits (see table 5). Conclusion: This study found that regular users of bitter kola enjoy better health than non-regular users and that both regular and non-regular user agrees to the medicinal properties of bitter kola. These research findings help to remove the assumptions about the health benefits of bitter kola and replaced them with actual research evidence.
\end{abstract}

Keywords Anti-oxidant, Bitter Kola, Flavonoid, Health Benefits, Plant Medicine, Phytochemical

\section{Introduction}

The ultimate aim of World Health Organisation (WHO) Plant or Traditional Medicine strategy for 2014-2023 is to harness the use of plant medicine to improve population health. The WHO data demonstrated that of 129 countries, 80 per cent recognised the use of plants' medicine. [4] The use of traditional medicine is being practiced in numerous countries of the world, with positive outcomes on the health of the people. [5] Martins Ekor (2014) citing Committee on the use of Complementary and Alternative Medicine by the American Public, Board on Health Promotion, and Disease Prevention, Institute of Medicine, posited that in recent times the use of plant remedies as complementary and alternative medicines has gained wide acceptance in Europe, North America and Australia. In other words, plants' medicines are enjoying increase acceptance and represent a considerable proportion of the global drug market. [6]

The main reason given for encouraging plant remedies in developed countries could be found in the belief that they promote natural healthier living. Plants' medicines are viewed in the developed countries as a balanced and moderate approach to healing without the adverse side effects from costly pharmaceutical drugs. [6] According to Parle and Bansal, (2006), plants' remedies have now become alluring as they help the body's natural capacity for self-repair, given appropriate conditions to take full effect. [7] Ekor (2014) citing Bandaranayke (2006) enumerated the following contributory factors for the current resurgence of public interest in traditional remedies:

1) various claims on the efficacy or effectiveness of traditional medicines,

2) preference of consumers for traditional remedies and a growing interest in alternative therapy,

3) a belief that traditional medicines are superior to manufactured products, 
4) dissatisfaction with the results from orthodox pharmaceuticals and the belief that traditional medicines might be effective in the treatment of certain diseases where conventional medicines have proven to be ineffective,

5) improvements in the quality, efficacy, and safety of traditional medicines with the development of science and technology,

6) patients' belief that their physicians have not properly identified the problem; hence the feeling that traditional remedies are another option, and

7) a movement toward self-medication. [6]

Marketing strategies such as the use of sales representatives and numerous advertisements in the mass media including television and radio programs have also enormously increased awareness of traditional medicines. [7]

The reason given for encouraging the use of traditional remedies in developing countries is mainly due to high cost and misuse western pharmaceutical drugs. A recent study has shown that medicinal plants have been used as remedies for all sorts of diseases afflicting mankind since ages in many parts of the world. The study added that about 80 per cent of the people in rural communities of many developing countries use medicinal plants as the primary source of medicine. The study added that urban communities in recent times have increased use of plant remedies due to frequent use and misuse of pharmaceutical drugs that have led to the emergency of resistant strains of common pathogens as well as increased incidence of adverse effects associated with the usage. [8]

The use of plants in the traditional medical practice has remained the mainstay of primary health care delivery involving between 250,000 to 400,000 species spread across the globe. [9] Bitter kola is one of the medicinal plants, which has been used in African ethno medicine because of its purgative, antiparasitic, antimicrobial properties. [10] Bitter kola is botanically known as Garcinia Kola. It is flowering plant found in subtropical or tropical moist lowland forests of Nigeria, Senegal, Sierra Leone, Liberia, Ghana, Gabon, Ivory Coast, Democratic Republic of the Congo, Cameroon and Benin Republic.

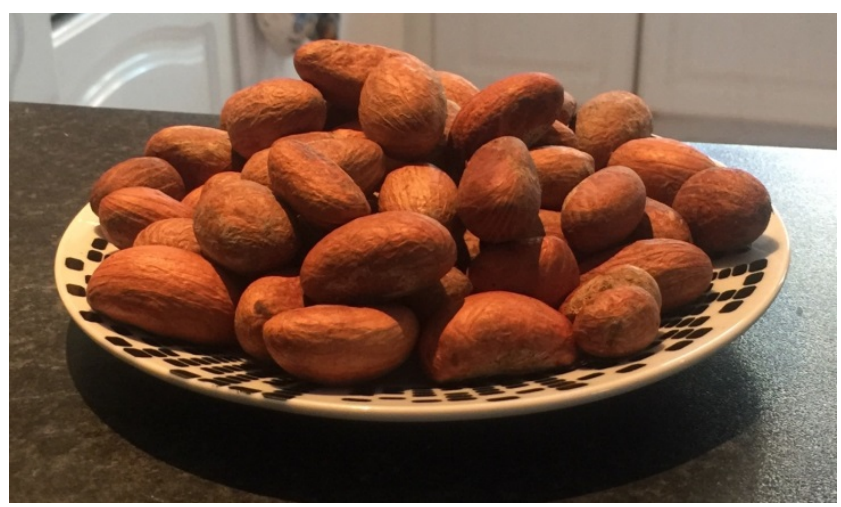

The name bitter Kola came from the bitter astringent and resinous taste, which is followed by a slight sweetness you get from chewing the kola. In Nigeria, bitter Kola is referred to differently by the three main tribes. It is called aku-ilu, adu or ugolo in Igbo, orogbo in Yoruba and namijingworo in Hausa. It is highly valued in Africa and used for hospitality during cultural and social ceremonies. [10]

The phytochemical property of bitter kola has attracted the attention of many scientists in the last few decades. Phytochemicals are non-nutritive chemicals that plants produce to protect themselves from diseases conferred from diets high in fruits, vegetables, beans, cereals, and plant-based beverages such as tea and wine. [11] Phytochemicals are known to possess antioxidants and anti-microbial properties that make them valuable to human. For example, Icheku (2006) in a review of scientific literature found that antioxidant protects human cells against oxidative damage and reduce the risk of developing certain types of cancer. [12] One study posited that bitter kola protects against the oxidation of lipoprotein, through antioxidant and scavenging activities of flavonoid. [13] Another study reported that antioxidant of bitter kola acts to either inhibit or slow down the progression of symptomatic knee osteoarthritis. It acts as a scavenger to remove the particles that have been observed on the surfaces of human articular cartilage following trauma and osteoarthritis. The study added that antioxidant also acts to limits the oxidative conversion of amino acid by reactive oxygen species to other damaging fatty acid products and acts by restoring and maintaining the balance of fatty acids in osteoarthritis. [14] Phytochemicals bind physically to cell walls thereby preventing the adhesion of pathogens to human cell walls. Carotenoids found in fruits, Polyphenols found in tea and grapes and Flavonoids found in fruits and vegetables are examples of phytochemicals with antioxidant. [13, 14]

Given the chemical structure of phytochemicals, they can be broken into the following three groups; Phenolic Acids, Flavonoids, and Stilbenes or Lignans and flavonoids are the most diverse group of phytochemicals that protect humans against diseases. [15] Some of the phytochemicals' compounds isolated from bitter kola include oleoresin, tannin, saponins, alkaloids, cardiac glycoside, bioflavonoids such as kolaflavonone, and 2 hydroxyflavonoids. The recently discovered chromanols (phytochemical compounds) such as garcioic and garcinal together with - tocotrienol were also reportedly isolated from bitter kola. [16] Studies cited by Heneman (2008) of the Cooperative Extension Center for Health and Nutrition Research, Department of Nutrition in the University of California show clear link between flavonoid intakes and improved mortality and mortality rate in human studies. For example, one study showed a significant inverse association between flavonoid intake and myocardial infarction. Another study, which compared the diets of men living in seven different countries, found that the 
consumption of flavonoids was responsible for 25 percent of the observed difference in mortality rates in the seven countries studied. [15] Another study showed that bitter kola which has an abundance of flavonoid prevents neuronal damage in the malnourished mice. [17]

The main reason given for growing global acceptance of traditional remedies is the dissatisfaction with the results from orthodox pharmaceutical drugs and the belief that plant medicines might be effective in the treatment of certain diseases where the orthodox medicines have proven to be ineffective or with inherent adverse side effects. [18] In other words, there is a growing acceptance of plant medicine in both developed and developing countries for all kinds of conditions and situations where conventional treatment options have been limited. [19] One study published in the Pharmaceutical Journal predicted that the acceptance of plant medicine will grow within the next few years as the evidence base of many plant medicinal products is likely to increase significantly with the application of new technologies that would enable a more holistic understanding of how all the constituents in a traditional medicine work together and act on biological systems. [20]

However, one study openly criticized plant medicine for lack of scientific evidence to establish their safety and efficacy. [1] Another study stated that, although the use of complementary and alternative Medicine (CAM) has increased over the past twenty years, there is limit research evidence to support its use. [2] Similarly, a study on the efficacy of traditional remedies for managing insomnia found that there are few scientific studies on the therapeutic potential and safety of commonly use traditional remedies. The study also found that the results of few available scientific studies are inconclusive or contradictory. [3]

Bitter kola is highly valued plant medicine and used widely in Africa for its medicinal properties [10], but there is a disparity between highly prevalent use of the plant and solid evidence of its health benefits. These researchers were unable to find any previous research that has been carried out to explore this topic using quantitative research method. A study is therefore required to fill this gap in knowledge. The purpose of this study is to fill the identified gap, and the method of research allowed the researcher to formulate and answer the following question.

\subsection{Research Question}

Does ingesting bitter kola (Garcinia kola) provide any derivable health benefits or health improvement for regular users?

\subsection{Research Aim and Objective}

A preliminary study shows that there is a disparity between highly prevalent uses of the bitter kola as a medicinal plant and solid evidence of its health benefits.
Thus, the aim of this study is to determine whether bitter kola provides any health benefit to its regular users. The objective is to collect data on regular users and non-regular consumers of the bitter kola and compare the two sets of data to answering the research question.

\section{Research Methodology}

To meet the aim and objective of this study, a comparative cross-sectional quantitative research method was chosen because it is probably the most commonly used research method for comparing, quantifying or measuring health benefits. Crichton (2001) postulated that quantitative research method, in general, has its origins in positivism; a world of objective reality that can be compared, measured or quantified. [21] In Pollit and Beck (2014) view, the method lends itself to be interpreted in a quantifiable way without allowing for manipulation of respondents outcomes. [22]

Quantitative data, however, is numerical and involves using statistical models and the numerical information that is collected using research tools as objectively as possible. [23] The quantitative approach made it possible for this study to be reproducible and its findings generalisable to other communities where ingesting bitter kola is prevalent. Furthermore, these researchers have a positivist view, in that the finding of the study is identified by unbiased, impartial observers who look closely and carried out the study in a detached and unemotional way.

Finally, in a comparative cross-sectional study, the researcher measures the outcome and the exposures in the study participants at the same time. [21, 22, 23]. As the initial study shows that most adults in Igbuzor ingest bitter kola for ostensible health benefits; the research method enables these researchers to compare the health status of regular and non-regular consumers of the bitter kola within the Igbuzor community. The research findings help to remove the assumptions about the health benefits of ingesting the bitter kola and replace them with actual data gathered using the comparative cross-sectional research tool. [21] [22]

\subsection{Sample Selection}

As it was impossible to gather information from an estimated population of 566,310 people in Igbuzor town, a sample of 300 adults was randomly selected. [24] A sample is a subsection of a population selected to participate in a research study. [25] A survey which is based on some form of random sampling technique will produce a sample which is representative of the particular population under study and will produce findings which may be generalised to the wider population. [26] Therefore, the use of random sampling technique in this study is intended to give every member in the population frame equal chance of being 
selected, thereby produce a sample that is representative. [25] [26]

The survey took place between June 2015 and September 2015. Out of the 300 questionnaires that were handed out, 210 were returned by the first week of September. Additional 60 questionnaires were returned by the last day of September after many follow up prompts and reminders, a total of 274 questionnaires were returned.

The inclusion criteria required that any adult between aged 18 and 70 was included, irrespective of gender. Any adult who was too sick to participate or unable to write a response to the questions was excluded. Consent was sought using purposefully designed consent form.

\subsection{Data Collection}

Quantitative researchers usually use methods of data collection, which is then transformed into numerical data to be statistically manipulated to answer the research. [27] Quantitative data is often gathered through questionnaires that are carefully developed and structured to provide the researcher with numerical data that can be explored statistically and yield a result that can be generalised to a larger population. [26] The data on the use of bitter kola was, thus, collected using a purpose-designed, cross-sectional anonymous questionnaire, administered on a single occasion. The data were collected using questionnaire consisting of 5 questions, which translated into statements for Likert scale. The questionnaire took approximately 20 minutes to complete. The questionnaire design was informed by Burgess (2001) Guide to the design of questionnaires for research, which demonstrated that a crucial element of good research design concerns are making sure that the questionnaire design addresses the needs of the research. [28]

The pilot study was conducted on 20 members of Isunambagu social club of Ibusa and Ibusa Development Union United Kingdom branch. The aim of the pilot study is in line with some scholars' view that it is a mini version of the main study designed to help the researchers determine the feasibility of the study and reliability of the data collecting tool. [29] Thus, subsequent adjustments were made to the questionnaire based on the outcome of the pilot study.

The data collection for this study was carried using Likert Scale, which allows the attitude of respondents towards the use of bitter kola to be measured. In each question, a statement is presented in which the respondents indicated a degree of agreement or disagreement in a multiple choice type format. Likert Scale assumes that the strength or intensity of the experience is linear, i.e., on a continuum from strongly agree to strongly disagree; makes the assumption that attitudes can be measured and thus allows quantitative data to be collected and analysed. [30]

\subsection{Data Analysis}

To analyse the Likert scale data, these researchers 'coded respondents' responses as follows. $1=$ Strongly disagree $2=$ Disagree $3=$ Neutral $4=$ Agree $5=$ Strongly agree. As Likert-type data is usually ordinal data, we could only say that one score is higher than another, not the distance between the points. According to Marateb et al. (2014), ordinal data makes more sense when converted to interval data using interval scale. Interval scale is a metric scale that has constant, measure the equal distance between values, but the zero point is arbitrary. It is measured on a linear scale, and can take on positive or negative values. [30] Thus, the interval scale used for this data analysis is designed to show how the respondents agree, neutral or disagree with statements about their use of bitter kola on a 5 -point scale. For example, the Likert scale uses the response categories of strongly agree, agree, disagree, strongly disagree, neither agree nor disagree, combine agree and strongly agree on responses into one category and the disagree and strongly disagree into another. This gives us three categories of responses: agree, disagree and neutral.

The use of Likert scale in this study yielded ordinal data, which were converted to interval data using interval scale. [31] Inferential statistics for ordinal data, on the other hand, uses non-parametric tests, such as chi-squared, because parametric tests require internal data. [32] Thus, to display the distribution of respondents' responses i.e. (that agree, neutral, disagree) these researchers used percentages and a bar chart as illustrated below. In addition to the use of percentages and bar charts to display a measure of responses, the chi-squared statistical test was used to show the correlation between the data and the question. The aim of applying chi-squared statistical test is to indicate whether a statistically significant relationship exists within the data relationships.

The data analysis, therefore, involves descriptive analysis and testing for significance of associations, which were carried out within the collected data. These researchers have chosen descriptive statistics because it is an appropriate approach when large quantities of data have been collected. [33] The descriptive statistics made it possible for the data to be organised and presented using tables and graphs in line with quantitative research method. The analysed data using descriptive statistics yielded results that can be generalised to a larger population. [33]

\section{Results}

\subsection{Response Rate}

A total of 300 questionnaires were handed out to respondents. Of these, 26 questionnaires were omitted from the data analysis, as they were missing responses amounting to 8.7 per cent drop outs. Therefore, the final response rate was 274 which amounted to 91 per cent response rate. 


\subsection{Number of Male and Female Respondents}

Table 1. Total respondents by gender

\begin{tabular}{|c|c|c|}
\hline Total Respondents $\mathrm{n}=274$ & Male & Female \\
\hline 274 & 155 & 119 \\
\hline
\end{tabular}

\section{Respondents by Gender}

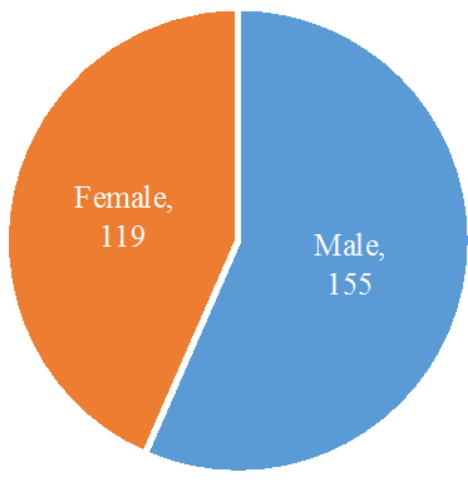

Figure 1. Pie chart showing respondents by Gender
The table and figure above show the distribution of Males and Females surveyed. The results show that most of the respondents are Males.

Table 2. Length of time respondents have been ingesting Bitter Kola by Gender

\begin{tabular}{|c|c|c|c|}
\hline $\begin{array}{c}\text { Total Respondents } \\
\mathrm{n}=274\end{array}$ & Male & Female & $\begin{array}{c}\text { Number of } \\
\text { respondents }\end{array}$ \\
\hline $\begin{array}{c}\text { Not regularly, once in a while or } \\
\text { never ingested bitter kola }\end{array}$ & 50 & 66 & 116 \\
\hline Regularly for about 12 months & 5 & 6 & 10 \\
\hline $\begin{array}{c}\text { Regularly for at least 12 months but } \\
\text { less than two year }\end{array}$ & 7 & 7 & 22 \\
\hline $\begin{array}{c}\text { Regularly for at least 24 months but } \\
\text { less than three years }\end{array}$ & 23 & 10 & 43 \\
\hline $\begin{array}{c}\text { Regularly for at least 36 months but } \\
\text { less than four years }\end{array}$ & 20 & 5 & 43 \\
\hline $\begin{array}{c}\text { Regularly for at least 48 months but } \\
\text { less than five years }\end{array}$ & 26 & 15 & 48 \\
\hline $\begin{array}{c}\text { Regularly for than five years or } \\
\text { more }\end{array}$ & 24 & 10 & 274 \\
\hline Total & 155 & 119 & 44 \\
\hline
\end{tabular}

chi-square $=20.763, \mathrm{df}=6, \mathrm{p}=0.002$

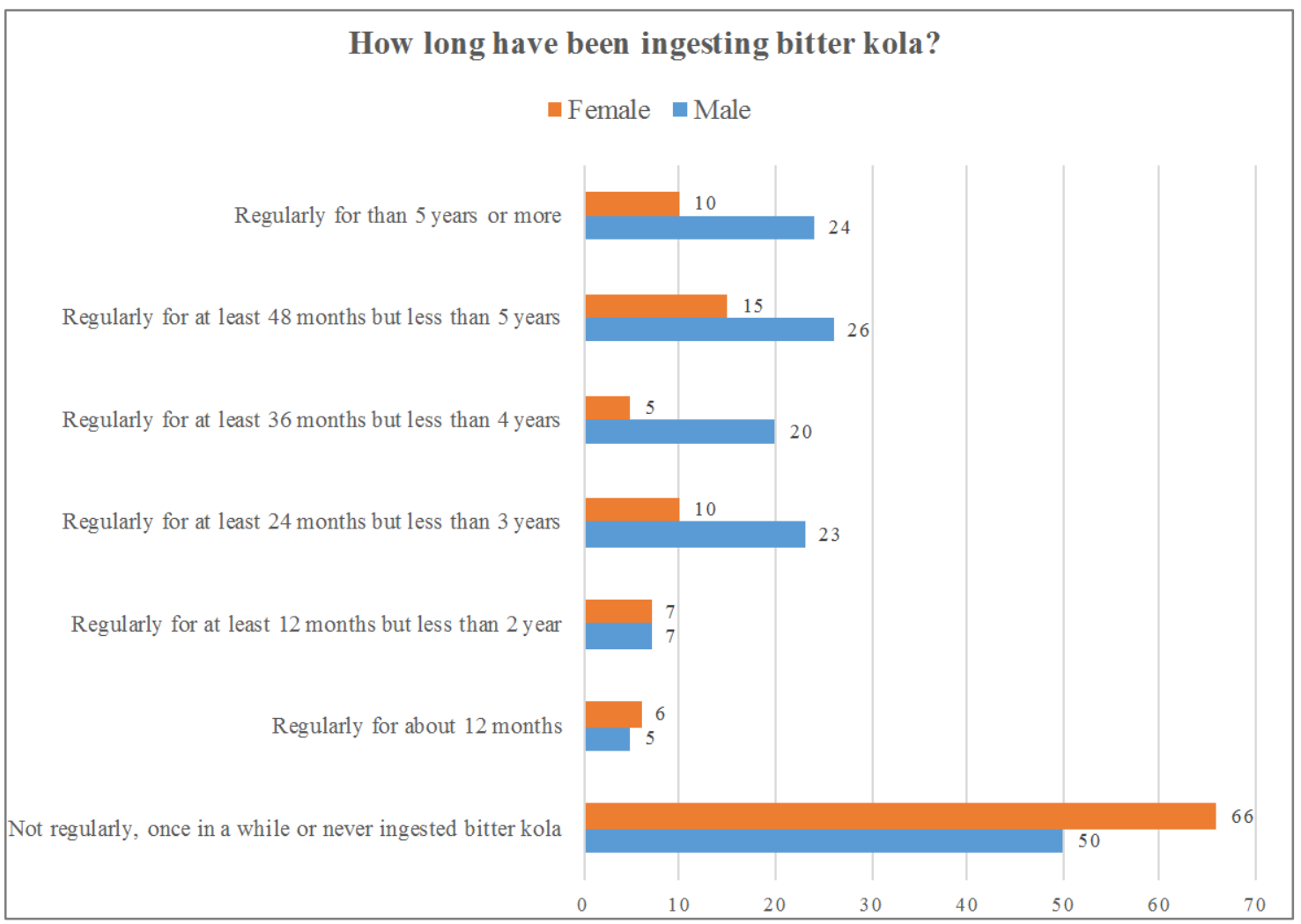

Figure 2. Bar charts comparing the length of time respondents have been ingesting bitter kola by gender

Table 2 shows the length of time respondents have been ingesting Bitter Kola by Gender. Figure 2 Bar charts compares the length of time respondents have been ingesting Bitter Kola by Gender. The results show the significant association between the length of time and Gender. Furthermore, the results indicate that Males are more likely to have been ingesting Bitter Kola regularly than Females. 
Table 3. Response by the regular users of bitter kola to the statements about their overall health by gender

\begin{tabular}{|c|c|c|c|c|c|c|c|}
\hline Statements & Gender & Disagree & Neutral & Agree & Chi-Square & $\mathrm{df}$ & $\mathrm{p}$-value \\
\hline \multirow{2}{*}{ My health is excellent } & Male & 4 & 3 & 16 & \multirow{2}{*}{0.831} & \multirow{2}{*}{2} & \multirow{2}{*}{0.66} \\
\hline & Female & 1 & 2 & 18 & & & \\
\hline \multirow{2}{*}{ My health is very good } & Male & 4 & 3 & 33 & \multirow{2}{*}{0.094} & \multirow{2}{*}{2} & \multirow{2}{*}{0.954} \\
\hline & Female & 3 & 2 & 18 & & & \\
\hline \multirow{2}{*}{ My health is good } & Male & 2 & 2 & 31 & \multirow{2}{*}{0.171} & \multirow{2}{*}{2} & \multirow{2}{*}{0.918} \\
\hline & Female & 1 & 1 & 23 & & & \\
\hline \multirow{2}{*}{ My health is fair } & Male & 4 & 7 & 18 & \multirow{2}{*}{2.121} & \multirow{2}{*}{2} & \multirow{2}{*}{0.346} \\
\hline & Female & 2 & 5 & 22 & & & \\
\hline \multirow{2}{*}{ My health is poor } & Male & 11 & 13 & 4 & \multirow{2}{*}{0.409} & \multirow{2}{*}{2} & \multirow{2}{*}{0.815} \\
\hline & Female & 10 & 10 & 1 & & & \\
\hline \multirow{2}{*}{ Total } & Male & 25 & 28 & 102 & \multirow{2}{*}{0.306} & \multirow{2}{*}{2} & \multirow{2}{*}{0.858} \\
\hline & Female & 17 & 20 & 82 & & & \\
\hline
\end{tabular}

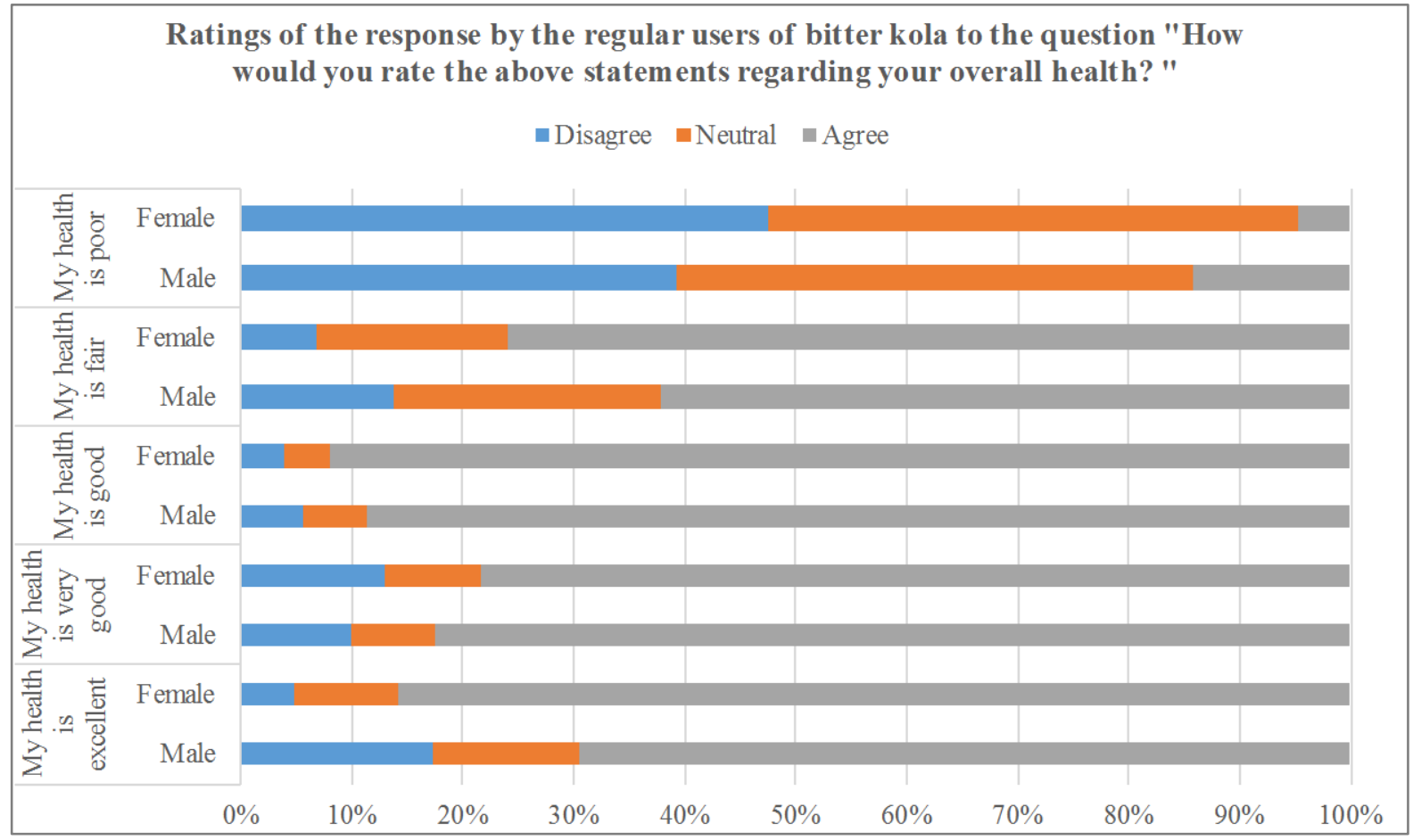

Figure 3. Bar charts comparing the response rate by the regular users of bitter kola to the statements about their overall health by gender

Table 3 shows the responses of Regular users of Bitter Kola when grouped as to Males and Females with regards to certain statements on Bitter Kola. The results show no significant association between the agreeableness of the statements when grouped as to Gender. This means that the respondents regardless of Gender Mostly Agree to good health status while ingesting Bitter Kola. 
Comparative Cross-sectional Quantitative Study of Health Status among Consumers of Bitter Kola in Igbuzor Community Living in Oshilmili North Local Government Area of Delta State

Table 4. Response by the non-regular users of bitter kola to the statements about their overall health by gender

\begin{tabular}{|c|c|c|c|c|c|c|c|}
\hline Statements & Gender & Disagree & Neutral & Agree & Chi-Square & $\mathrm{df}$ & p-value \\
\hline \multirow{2}{*}{ My health is excellent } & Male & 23 & 0 & 9 & \multirow{2}{*}{1.973} & \multirow{2}{*}{2} & \multirow{2}{*}{0.373} \\
\hline & Female & 12 & 1 & 4 & & & \\
\hline \multirow{2}{*}{ My health is very good } & Male & 21 & 0 & 6 & \multirow{2}{*}{2.406} & \multirow{2}{*}{2} & \multirow{2}{*}{0.3} \\
\hline & Female & 20 & 2 & 4 & & & \\
\hline \multirow{2}{*}{ My health is good } & Male & 31 & 3 & 9 & \multirow{2}{*}{1.999} & \multirow{2}{*}{2} & \multirow{2}{*}{0.3681} \\
\hline & Female & 21 & 0 & 5 & & & \\
\hline \multirow{2}{*}{ My health is fair } & Male & 14 & 4 & 8 & \multirow{2}{*}{0.552} & \multirow{2}{*}{2} & \multirow{2}{*}{0.7588} \\
\hline & Female & 14 & 2 & 7 & & & \\
\hline \multirow{2}{*}{ My health is poor } & Male & 10 & 3 & 14 & \multirow{2}{*}{0.344} & \multirow{2}{*}{2} & \multirow{2}{*}{0.84198} \\
\hline & Female & 11 & 4 & 12 & & & \\
\hline \multirow{2}{*}{ Total } & Male & 99 & 10 & 46 & \multirow{2}{*}{0.33} & \multirow{2}{*}{2} & \multirow{2}{*}{0.8466} \\
\hline & Female & 78 & 9 & 32 & & & \\
\hline
\end{tabular}

\section{Ratings of Statements regarding overall Health for Bitter Kola Non Regular} users

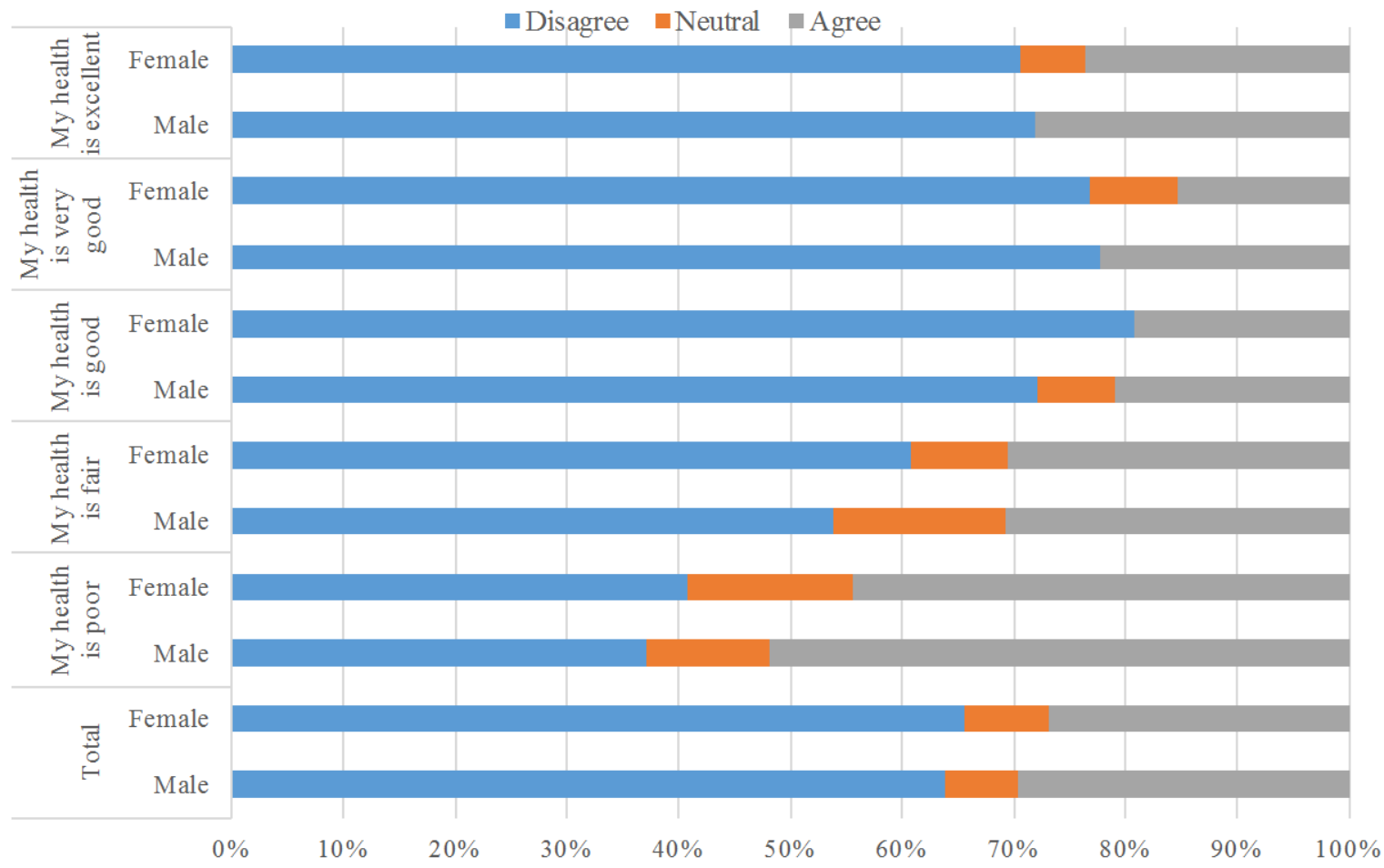

Figure 4. Bar charts comparing the response rate by the non-regular users of bitter kola to the statements about their overall health by gender

Table 4 shows the responses of Non Regular users of Bitter Kola when grouped as to Males and Females with regards to certain statements on Bitter Kola. The results show no significant association between the agreeableness of the statements when grouped as to Gender. This means that the respondents regardless of Gender Mostly Disagree with good health status while ingesting Bitter Kola. 
Table 5. Distribution of responses by gender when respondents were asked whether they ingest bitter kola for its health benefits

\begin{tabular}{|c|c|c|c|c|c|c|c|c|c|}
\hline \multirow{3}{*}{ Statements } & \multirow{3}{*}{$\begin{array}{c}\text { Gender } \\
\text { Male }\end{array}$} & \multirow{3}{*}{$\begin{array}{c}\begin{array}{c}\text { Number of } \\
\text { respondents to the } \\
\text { statement }\end{array} \\
150\end{array}$} & \multicolumn{2}{|c|}{ Disagree } & \multicolumn{2}{|c|}{ Neutral } & \multicolumn{2}{|c|}{ Agree } & \multirow{3}{*}{$\begin{array}{c}\begin{array}{c}\text { Total survey } \\
\text { respondents }\end{array} \\
155\end{array}$} \\
\hline & & & No. & $\%$ & No. & $\%$ & No. & $\%$ & \\
\hline & & & 0 & 0.00 & 8 & 5.33 & 142 & 94.66 & \\
\hline \multirow{3}{*}{$\begin{array}{l}\text { I ingest bitter kola for its health } \\
\text { benefits }\end{array}$} & \multirow[t]{2}{*}{ Female } & \multirow[t]{2}{*}{115} & No. & $\%$ & No. & $\%$ & No. & $\%$ & \multirow[t]{2}{*}{119} \\
\hline & & & 0 & 0.00 & 5 & 4.34 & 110 & 95.65 & \\
\hline & Total & 265 & 0 & 0.00 & 13 & 0.00 & 242 & 0.00 & 274 \\
\hline
\end{tabular}

chi-square $=0.136, \mathrm{df}=2, \mathrm{p}=0.934$

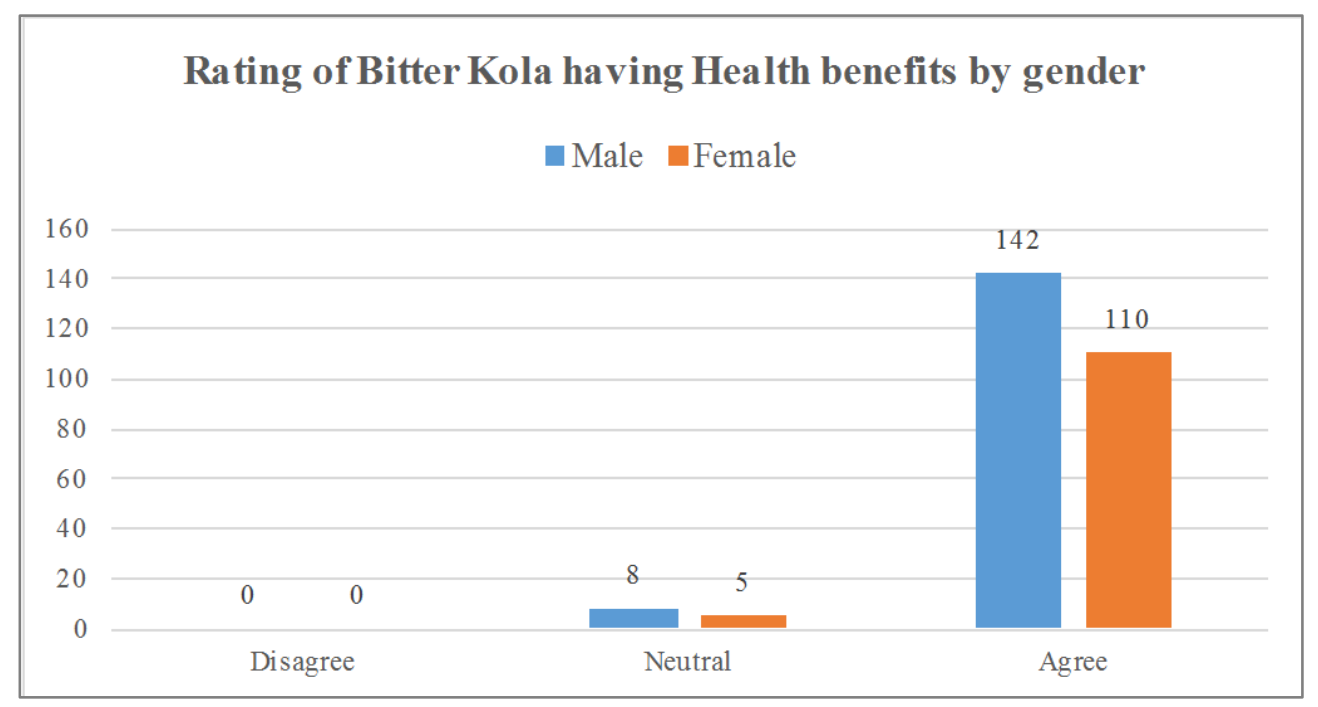

Figure 5. Bar charts comparing the response rate by gender when respondents were asked whether they ingest bitter kola for its health benefits

Table 5 shows the distribution of responses by Gender when asked whether they ingest Bitter Kola for its Health Benefits. The chi-square results show no significant association between the agreeableness of the question when grouped as to Gender. This means that both Genders agree that they ingest Bitter Kola for its health benefits.

\section{Discussion of Findings}

The research question for this study is; does bitter kola provide any derivable health benefits or health improvement for regular users? The objective is to collect gender specific data on regular and non-regular consumers of the bitter kola and compare the two sets of data and thus answer the research question. The data were collected using questionnaire consisting of 5 questions, which were translated into Likert statements.

The results show that irrespective of gender $n=139$ regular users agreed to excellent and good health while ingesting bitter kola in comparison to $\mathrm{n}=37$ non-regular users who agreed to the same statements. The results further show that both genders $n=142(94.66 \%)$ male and $\mathrm{n}=110(95.65 \%)$ female respondents agree that they ingest better kola for its health benefits.
These findings are supported by a study, which demonstrated that both the seed and leaf of bitter kola have antibacterial activity on clinical isolates of Escherichia coli, Salmonella typhi including Streptococcus pyogenes and Staphylococcus aureus. The antibacterial activity of the bitter kola is attributed to these components of the seed and leaf extracts. The acclaimed anti-virus- and anti-bacterial activities of bitter kola demonstrated by the research data were attributed to the phytochemical property of the kola. [35] One study also found that the high rated anti-virus and bacterial activities of bitter kola may be attributed to its active compound known as a dimeric flavonoid, which is one of phytochemicals compounds isolated from bitter kola. [17] Another study demonstrated that Baicalin, a flavonoid isolated from Scutellaria baicalensis (Lamiaceae), inhibits HIV-1 infection and replication. Baicalein and other flavonoids such as Robusta flavone and hinokiflavone have been shown to inhibit HIV-1 and reverse transcriptase. [37] Some scholars studied the properties of four types of flavonoid; quercetin, hesperetin, naringin, and daidzein at different stages of dengue virus type- 2 infection and replication cycle. They found that quercetin type flavonoid to be most effective against DENV-2 in Vero cells. [36]

Another study showed that phytochemical from bitter kola could successfully treat the virus that causes Ebola 
hemorrhagic fever by halting multiplication of the virus in laboratory rats. If repeated in humans, this would give the body a chance to fight off the virus. Dr. Maurice Iwu, who set up and heads the Bio resources Development and Conservation Programme, led the research team and announced the discovery at the 16th International Botanical Congress in St Louis in the US. [37]

The phytochemical property of biter kola has attracted the attention of many scientists in recent times. [14] One study demonstrated that phytochemicals found in bitter kola possess antioxidants properties. Antioxidant protects human cells against oxidative damage and reduces the risk of developing certain types of cancer. It inhibits proliferation of cancer cells as well as alters cellular redox status. The study added that bitter kola protects against the oxidation of lipoprotein, through antioxidant and scavenging activities of flavonoid. [13] Several studies reviewed by Wachtel-Galor, et. el. (2011) showed that consumption of antioxidant-rich plants helps prevent cancer. [38] In other words, major public health benefits could be achieved by substantially increasing consumption of the antioxidant-rich foods. [38]

Finally, this present study confirms the findings of the above studies from the perspective of bitter kola having antioxidant properties. Antioxidants, as alluded to earlier, protect cellular components from oxidative damage, which is likely to decrease the risk of mutations and carcinogenesis and also protect immune cells, allowing them to maintain immune surveillance and response. [38] The mechanisms for antioxidant action include suppression of Reactive Oxygen Species (ROS) formation. ROS are chemically reactive molecules that contain oxygen and form as a natural byproduct of the normal metabolism of oxygen, which has important roles in cell signaling and homeostasis. Some studies posited that antioxidant suppresses ROS formation either by inhibition of enzymes or by chelating trace elements involved in free radical generation. [39] Similarly, flavonoid, which is one of the phytochemicals compounds isolated from bitter kola, inhibit the enzymes involved in ROS. [17] Flavonoids possess many biochemical properties, but the best-described property of almost every group of flavonoids is their capacity to act as antioxidants. [40]

One study also cited by Kumar and Pandey, (2013) identified several mechanisms by which flavonoids act to prevent cancer. The mechanisms of action of flavonoids include down-regulation of mutant p53 protein; cell cycle arrest; tyrosine kinase inhibition; inhibition of heat shock proteins; estrogen receptor binding capacity; inhibition of expression of Ras proteins. The mutations of p53 are claimed to be among the most common genetic abnormalities in human cancers. Inhibition of expression of the $\mathrm{p} 53$ was found to result in the arrest of cancer cells in the G2-M phase of the cell cycle. [41] Flavonoids were also found in the down-regulate expression of a mutant p53 protein to nearly undetectable levels in human breast cancer cells. [42] The induction of cancer cell apoptosis by flavonoids is associated with their ability to inhibit fatty acid synthase activity. [43]

\section{Study Limitations}

Cross-sectional studies are known to be quick, easy, and cheap to be carried out. They are usually based on a questionnaire survey. However, a cross-sectional study is often liable to non-response bias if participants who consent to take part in the study differ from those who do not, resulting in a sample that is not representative of the population. This limitation has little, or no impact on this study as 6 out of the 300 participants who signed the consent form dropped out. The study, however, may be limited by the sampling method used. Surveys are dependent upon the chosen sampling frame, and the representativeness of any survey is entirely dependent upon the accuracy of the sample used. This study used random sampling technique, which was intended to give every member in the population frame equal chance of being selected, thereby produce a sample that is representative. Although random sampling is known to be an unbiased approach to surveying, sample selection bias may occur. A representation of the full population is skewed when a sample set of the sampling frame is not inclusive enough. [26]

This study may also be limited by the Likert scale used for our data collection. Likert Scale questions are limited from the perspective of being uni-dimensional. In other words, they only gave our respondents certain amount of choices; implying that the space between each possibility is equidistant, which is not always the case in real life. However, the benefits of Likert Scale questions outweigh this main limitation. For example, Likert Scale a universal method of collecting data, mainly because it is easy to use by researchers and also easy to understand by respondents. The responses to the questions are easily measurable, and since it does not require the respondents to provide a simple and concrete yes or no answer, it does not force them to take a stand on a particular topic, but allows them to respond in a degree of agreement. [44]

It is important to stress at this juncture that every effort was made to minimise any impact these limitations might have on the outcome of this study. For example, to minimise sample selection bias, a broadly based sample was selected from the sample frame and we ensured that an adequate number of respondents from the sample was received. Much as it was easy to use Likert Scale in our data collection, due diligence was employed when working with the quantitative data, such as, tabulation of results, plotting of graphs, analysis of results and drawing of conclusions from the responses. We were guided by Pollit and Beck, (2014) requirement that quantitative data must lend itself to be interpreted in a quantifiable way without 
allowing for manipulation of respondents outcomes. [25]

Finally, these limitations are in no way affect the value and contribution of this study to knowledge. For example, to ensure that quantitative study is trustworthiness and a significant element of academic research, the research design should guarantee that same data and methods give same conclusions (objectivity); conclusions are correct (deductive methods, e.g., use of statistical data), and that the results can be independently verified or reproduced by the scientific community. [45] These qualities are crucial for such study to be received into the pantheon of knowledge or received as a valued contribution to knowledge. Thus, these researchers ensured that this study's aim and objectives are clarified; ensured that the research methods and the sample chosen are good for the research and not biased; ensured statistical calculations, and the interpretation of the results are correct and verifiable. The approach ensures that the finding of the study is reproducible and generalisable to other communities ingesting bitter kola.

\section{Funding}

There was no funding sought for this piece of research, as monetary value can create bias. To further minimise bias, a maximum effort was deployed at the sample selection stage to achieve more interest than may be needed as large-scale drop out from the study could have had an adverse effect on the study outcome.

\section{Ethical Considerations}

This study was carried in the part of Nigeria where there is no requirement for ethical approval. However, it is imperative that ethical consideration should be given to any study involving human sample. According to Icheku (2012) ethics is the aspect of moral philosophy which helps professionals to consider what will be right (ethical) or what will be wrong (unethical) in their action and thus guide their decisions. [46] About research ethics Polit and Beck, (2010) posited that ethics is a system of moral values that is concerned with the degree to which research procedures adhere to professional, legal and social obligations to the study participants. [25] The responsibilities of academic researchers regarding ethical values include principles of respect for respondent's autonomy, beneficence, non-maleficence, and justice that are relevant to the conduct of any research. [47] Although no ethical approval was obtained for this study, these researchers were challenged by these ethical principles and in response consent form, and information sheet were designed and handed out to respondents. The information sheet summarised the purpose and justification of the study. It states that participation is entirely voluntary and that data collected will be confidential and anonymous. It also states that by completing the consent form the participant will be consenting to the study. By explaining these details and offering the opportunity to get in touch if they have any questions, we were able to ensure that participants have enough information to make an informed decision as to whether or not they want to participate in the study. We also ensured that participant read the information sheet and signed the consent form before completing the questionnaire. By offering a detailed information sheet and offering support where necessary, we were able to ensure that the participants were motivated rather than coerced. [48]

The participants' names were not used to protect anonymity; each questionnaire was provided with a number that made participants identifiable only by the number. Much as physical harm was not an issue in this study, we were mindful of potential psychological consequences needing sensitivity. We, therefore, informed all participants that if they feel that some parts of the questionnaire are too much sensitive for them to respond; they should feel free to withdraw from the study or choose not to answer the questions. The participants were protected from potential adverse effect by ensuring that information that they provide to us was used only for the achievement of this study's goal. Thus, this study produced ethical advantages by ensuring the research approach did not expose participants to possibly invasion of privacy and were merely exposed to events that occur in their community and the real world. In other words, they are already ingesting bitter kola as a habit without any know side effect. Thus, their participation in the study is not an unusual behaviour and would have taken place anyway.

\section{Conclusions}

The study demonstrated that regular users of bitter kola enjoy better health than non-regular users and that both regular and non-regular agree to the medicinal property of bitter kola. The health benefits of bitter kola have been attributed the phytochemical property of the kola. The phytochemicals found in bitter kola possess antioxidants properties. Antioxidant protects human cells against oxidative damage and reduces the risk of developing certain types of diseases. Thus, ingesting bitter kola on a regular basis protects humans against the oxidation of lipoprotein, through scavenging activities of flavonoid, which is a compound found in phytochemical.

The bitter kola is considered a safe, nontoxic, and effective alternative for many conventional drugs due to its distinguished therapeutic properties and multiple effects on various systems of the body. Its role as antibacterial and antiviral agents has been confirmed by the studies reviewed earlier. Such evidence-based information should then be disseminated to health care providers to enable them promote the use of bitter kola for its medicinal properties.

Finally, the overall conclusion is that this study made 
only small contribution to address the lack of robust human research on potential health benefits of ingesting bitter kola. Further research is recommended to measure the benefits of ingesting the bitter kola on specific health conditions such as a cough; catarrh and other cold symptoms. Additional study will be required to determine the bioavailability, optimal dosage, and bio-efficacy of the bitter kola.

\section{Author Contributions}

Dr. Vincent Icheku is the lead researcher. He conceived the study, designed the questionnaire, participant information sheet, consent form and carried out the pilot study. Dr. Ifeanyichukwu Fidelis Onianwah and Augustine Nwulia, identified the sample frame, administered the questionnaires to 300 participants selected at random and carried out the data collation. Dr. Icheku carried out the analysis and interpretation of the research data and wrote the script. The three researchers reviewed the script and approval of the final version for publication.

\section{Acknowledgements}

The research team would like to thank members of Ibusa Development Union (ICDU) UK branch and Isunambagu Social Club of Ibusa (ISCI), also UK branch for their participation in the pilot study. We would also like to thank the 274 respondents who voluntarily participated in the study. Thanks to Dr. Patrick Okonta for general encouragement and support for this study. To Umuezeogboli family, we owe a lot of gratitude for their cooperation in the course of the research work. Thanks to Mrs. Gloria Onianwah for the logistic support and participation in the collation of sample data. We also thank Mrs. Chinelo Icheku, Specialist Nurse Practitioner, Jenner Health Centre, UK National Health Service for providing guidance on the content of the disclaimer. Finally, we extend appreciation to Dr. Calvin Morley, Associate Professor of Nursing Research \& Diversity in Care, London South Bank University for review of the final script and useful advice for improvement.

\section{Disclaimer}

The finding of this study is provided for educational purpose only and should not be construed as medical advice or prescription. Readers should consult their family doctor or any other qualified health care professional on any matter relating to their health and well-being. In other words, these researchers and the publishers of the study are not responsible for any act of omission or commission arising from misuse of information contained in this publication.

\section{REFERENCES}

[1] Bent, S. (2008), Herbal Medicine in the United States: Review of Efficacy, Safety, and Regulation, J Gen Intern Med. 2008 Jun; 23(6): 854-859. Apr 16. doi: 10.1007/s11606-008-0632-y, http://www.ncbi.nlm.nih.gov/pmc/articles/PMC3931324/

[2] Fischer,F.H, Lewith,G., Witt,C. M., Linde K, Ammon, K, Cardini,F, Falkenberg, T., Fønnebø,V., Johannessen,H., Reiter,B., Uehleke,B., Weidenhammer,W., and Brinkhaus, B . (2014), High prevalence but limited evidence in complementary and alternative medicine: guidelines for future research, BMC Complement Altern Med. 2014; 14: 46.6.

doi:http://www.ncbi.nlm.nih.gov/pmc/articles/PMC393132 4/

[3] Liebert, M. A. (2012), Efficacy of herbal remedies for managing insomnia, Medical Press, July 18, http://medicalxpress.com/news/2012-07-efficacy-herbal-re medies-insomnia.html

[4] WHO (2013), Essential medicines and health products: WHO traditional medicine strategy: 2014-2023, World Health Organisation (WHO),

http://www.who.int/medicines/publications/traditional/trm strategy14_23/en/

[5] Qidwai, W., Alim, S.R., Dhanani, R.H., Jehangir, S., Nasrullah, A., Raza, A. (2003) Use of folk remedies among patients in Karachi Pakistan, Journal of Ayub Medical College, Abbottabad: JAMC. Volume 15, Issue 2, 2003 Apr-Jun, Pages 31-33

[6] Ekor, M. (2014), The growing use of herbal medicines: issues relating to adverse reactions and challenges in monitoring safety, Front Pharmacol. 2013; 4: 177. http:/www.ncbi.nlm.nih.gov/pmc/articles/PMC3887317/

[7] Parle M., Bansal N. (2006). Herbal medicines: are they safe? Natural Product Radiance. 5 6-14

[8] Ranjana, T. and Tripathi V.D (2015), Therapeutic Effect of Haridra (Curcuma Longa Linn.) in General and Oral Health, an International Journal of Research in AYUSH and Allied Systems, 1(2):40-43

[9] Adesuyi, A.O. Elumm, I.K. Adaramola, F.B. and Nwokocha, A.G.M. (2012), Nutritional and Phytochemical Screening of Garcinia kola, Advance Journal of Food Science and Technology 4(1): 9-14.

[10] Iwu, M. (1993), Handbook of African medicinal plants. CRC Press, Boca Raton, FL: CRC Press

[11] Arts, I.C. and P.C. Hollman, Polyphenols and disease risk in epidemiologic studies. Am J Clin Nutr, 2005: 81(1 Suppl): p. 317S-325S.

[12] Icheku, V. (2006), Degenerative Diseases of Ageing: Causes and Preventions, William Jacob Publishers, London

[13] Farombi E.O, Akanni O.O, Emerole G.O. (2002) Antioxidant and Scavenging activities of flavonoid extract 
(kolaviron) of Garcinia kola seeds. Pharmaceutical Biology. ; 40:107-16. doi: 10.1076/phbi.40.2.107.5838.

[14] Adegboye, M. F., Akinpelu, D. A., and Okoh, A. (2008) The bioactive and phytochemical properties of Garcinia kola (Heckel) seed extract on some pathogens, African Journal of Biotechnology Vol. 7 (21), pp. 3934-3938, 5 November, 2008 Available online at http://www.academicjournals.org/AJB ISSN 1684-5315 C) 2008

[15] Heneman, K., (2008), Some Facts about phytochemicals, Nutrition and Health Information Sheet, http://nutrition.ucdavis.edu/content/infosheets/fact-pro-phyt ochemical.pdf

[16] Terashima K, Takaya Y, Niwa M (2002). Powerful antioxidative agents based on garcinoic acid from Garcinia kola. Bioorgan. Med. Chem. 10(5): 1619-1625.

[17] Ajayi, S.A., Ofusori, D. A., Ojo, G. B, Ayoka, O. A., Abayomi, T. A.and Tijani, A. A. (2011), The microstructural effects of aqueous extract of Garcinia kola (Linn) on the hippocampus and cerebellum of malnourished mice, Asian Pac J Trop Biomed. 2011 Aug; 1(4): 261-265.doi: 10.1016/S2221-1691(11)60039-7

[18] Nagpal, M. and Sood, S. (2013) Role of curcumin in systemic and oral health: J Nat SciBiol Med. Jan-Jun; 4(1): 3-7.doi: 10.4103/0976-9668.107253, http://www.ncbi.nlm.nih.gov/pmc/articles/PMC3633300/

[19] Eisenberg DM, Davis RB, Ettner SL, Appel S, Wilkey S, Van Rompay M, Kessler RC: Trends in alternative medicine use in the United States, 1990-1997: results of a follow-up national survey. JAMA 1998, 280:1569-1575.

[20] Edwards, S.(2012), Use and efficacy of herbal medicines: Part 2 - clinical effectiveness - 2012 http://www.pharmaceutical-journal.com/research/perspectiv e-article/use-and-efficacy-of-herbal-medicines-part-2-clinic al-effectiveness/11106112.article The Pharmaceutical Journal 5 SEP 2012

[21] Crichton, N.J. (2001) Principles of statistical analysis in nursing and healthcare research, Nurse Researcher, 8(5), 4-16

[22] Polit, D. F. and Beck, C. T. (2014) Essentials Nursing Research Appraising Evidence for Nursing Practice. 8th ed. London: Wolters Kluwer Health, Lippincott Williams, and Wilkins.

[23] Biggam, J. (2015) Succeeding with you Masters Dissertation A step-by-step handbook. 3rd ed. Berkshire: Open University Press.

[24] Tripmondo (2017) Ibusa Destination Guide: Discover Ibusa, http://www.tripmondo.com/nigeria/delta-state/ibusa/

[25] Polit D.F. \& Beck C.T. (2010). Essentials of Nursing Research: Appraising Evidence for Nursing Practice, 7th edition. Wolters Kluwer Health | Lippincott Williams \& Wilkins, Philadelphia. Pp 74

[26] Mathers N, Fox N. and Hunn A. (2007) Surveys and Questionnaires. The NIHR RDS for the East Midlands / Yorkshire \& the Humber

[27] Gerrish K and Lacey A (2009) The Research Process in Nursing. Oxford: Blackwell Publishing
[28] Burgess, F., (2001) Guide to the design of questionnaires. Leeds: University of Leeds

[29] Burns, N., and Grove, S. K. (2005). The practice of nursing research: Conduct, critique, and utilization (5th ed.). St. Louis, MO: Elsevier Saunders

[30] Marateb, H.R., Mansourian, M., Adibi, P and Farina, D. (2014), Manipulating measurement scales in medical statistical analysis and data mining: $A$ review of methodologies, J Res Med Sci. 2014 Jan; 19(1): 47-56. http://www.ncbi.nlm.nih.gov/pmc/articles/PMC3963323/

[31] Blaikie N (2003) Analysing Quantitative Data. London: Sage Publications.

[32] Clegg F. (1998) Simple Statistics. Cambridge: Cambridge University Press.

[33] Lund Research (2013), Descriptive and Inferential Statistics, Lund Research Ltd, https://statistics.laerd.com/statistical-guides/descriptive-infe rential-statistics.php

[34] Ezeanya, C. C., and Daniel, E. O. (2013), Antibacterial activity of Garcinia Kola Seed and Leaf Extract on Some Selected Clinical Isolate, Science Journal of Microbiology, http://www.sjpub.org/sjmb/sjmb-298.pdf

[35] Zandi, K., Teoh, B. T., Sam, S. S., Wong, P. F., Mustafa, M. R. and Abubakar, S. (2011); the Antiviral activity of four types of bioflavonoid against dengue virus type-2," Virology Journal, vol. 8, article 560, 2011.

[36] Cushnie, T. P. T. and Lamb, A. J. (2005), Antimicrobial activity of flavonoids, International Journal of Antimicrobial Agents, vol. 26, no. 5, pp. 343-356, 2005.

[37] Halliwell. B. and Gutteridge, J. M. C. (1998), Free Radicals in Biology and Medicine, Oxford University Press, Oxford, UK.

[38] Davis W. L.and Matthew, S. B. (2000), "Antioxidants and cancer III: quercetin," Alternative Medicine Review, vol. 5, no. 3, pp. 196-208, 2000.

[39] Koen, B. Ruth, V. Guido, V. and Johannes, V. S. (2005), Induction of cancer cell apoptosis by flavonoids is associated with their ability to inhibit fatty acid synthase activity, Journal of Biological Chemistry, vol. 280, no. 7, pp. $5636-5645$

[40] Kumar, K. and Pandey, A. K. (2013)Chemistry and Biological Activities of Flavonoids: An Overview, The Scientific World Journal, Volume 2013 (2013), Article ID 162750,16 pages,

http://www.hindawi.com/journals/tswj/2013/162750/

[41] Yakubu, M.T, Quadri, A.L. (2012), Garcinia Kola Seeds: Is the Aqueous Extract a True Aphrodisiac in Male Wistar Rats? Afr J Tradit Complement Altern Med. 2012; 9(4): 530-535. http:/www.ncbi.nlm.nih.gov/pmc/articles/PMC3746641/

[42] Ralebona, N., Sewani-Rusike, C. R. and Nkeh-Chungag, B. N. (2012), Effects of ethanolic extract of Garcinia kola on sexual behaviour and sperm parameters in male Wistar rats, African Journal of Pharmacy and Pharmacology Vol. 6(14), pp. 1077 - 1082, 15 April,

[43] LaMarca, N. (2011), The Likert Scale: Advantages and Disadvantages, Field Research in Organisational 
Psychology,

https://psyc450.wordpress.com/2011/12/05/the-likert-scaleadvantages-and-disadvantages/

[44] Rasila, A. (2007) Quantitative research (outline), Helsinki University of Technology

http://www.cs.hut.fi/u/aura/kurssi/Quanti-handout_meeting 1.pdf

[45] Icheku, V. (2012), Understanding Ethics and Ethical Decision Making, SG Williams Publishing, London
[46] RMC (2011), Editorial: Research ethics: issues for midwives, Evidence-based midwifery,

https://www.rcm.org.uk/learning-and-career/learning-and-r esearch/ebm-articles/editorial-research-ethics-issues-for-mi dwives

[47] Walsh, M. Wigens, L. (2003) Introduction to Research: Foundations of Nursing and Health Care, Cheltenham, Nelson Thornes 